19 Revue d'histoire du XIXe siècle

Société d'histoire de la révolution de 1848 et des

révolutions du XIXe siècle

39 | 2009

Le monde de l'imprimé: des territoires aux acteurs -

Education et politique - Histoires politiques

\title{
Emmanuel de WARESQUIEL, Cent Jours. La tentation de l'impossible, mars-juillet 1815
}

Paris, Fayard, 2008, 704 p. ISBN : 978-2-213-62158-6. 28 euros.

Emmanuel Fureix

\section{OpenEdition}

Journals

Édition électronique

URL : http://journals.openedition.org/rh19/3952

DOI : 10.4000/rh19.3952

ISSN : $1777-5329$

Éditeur

La Société de 1848

Édition imprimée

Date de publication : 10 décembre 2009

Pagination : 163-165

ISSN : 1265-1354

Référence électronique

Emmanuel Fureix, «Emmanuel de WARESQUIEL, Cent Jours. La tentation de l'impossible, mars-juillet 1815 », Revue d'histoire du XIXe siècle [En ligne], 39 | 2009, mis en ligne le 26 mars 2010, consulté le 22 septembre 2020. URL : http://journals.openedition.org/rh19/3952 ; DOI : https://doi.org/10.4000/ rh19.3952

Ce document a été généré automatiquement le 22 septembre 2020.

Tous droits réservés 


\section{Emmanuel de WARESQUIEL, Cent Jours. La tentation de l'impossible, mars-juillet 1815}

Paris, Fayard, 2008, 704 p. ISBN : 978-2-213-62158-6. 28 euros.

\section{Emmanuel Fureix}

"Sire, cent jours se sont écoulés depuis le moment fatal où Votre Majesté, forcée de s'arracher aux affections les plus chères, quitta la capitale au milieu des larmes et de la consternation publique ». Ces célèbres mots, prononcés par le préfet de la Seine Chabrol, lors de la deuxième entrée royale de Louis XVIII dans Paris, le 8 juillet 1815 , donnent une unité artificielle à l'une des séquences les plus chaotiques de l'histoire. Les Cent-Jours abondent en parjures, trahisons, doutes. Les individus, a posteriori, recomposent un passé souvent tortueux. C'est ce climat particulier qu'Emmanuel de Waresquiel parvient à restituer. Le livre, adressé à un très large public, aurait pu ressasser tant d'histoires déjà écrites - parfois sur un mode fictionnel, telle la magnifique Semaine sainte d'Aragon (1958). Il n'en est rien. Son auteur utilise quantité d'écrits intimes - carnets, mémoires, archives privées diverses - jusque là non exploités. Mais l'essentiel n'est pas là : il déplace surtout le point de vue canonique sur les Cent-Jours. Non plus le Vol de l'Aigle et la régénération éphémère d'un Empire réconcilié avec la Révolution. Mais l'expérience, moins séduisante, d'un laborieux exil à Gand, et d'une reconquête douloureuse, celle d'un «Louis le Désiré» devenu «Cochon XVIII " puis roi des «fourgons de l'étranger ». Cette expérience n'est pas une victoire puisqu'elle signe l'échec d'un libéralisme de compromis, celui de la première Restauration de 1814. À ce titre, ces Cent-Jours adoptent le point de vue du vaincu et se moulent dans une histoire qui se veut, à la suite de Walter Benjamin, «à rebroussepoil $»^{1}$. À cette inversion de point de vue s'ajoute le souci constant de traquer les hésitations, les peurs, les transactions des individus. L'historien prend parfois les habits du moraliste, à propos d'honneur et de trahison, sans pour autant juger ceux qu'il met à nu. Enfin, il entreprend de restituer, aux côtés du bonapartisme révolutionnaire de 1815 , un « royalisme populaire » qu'il estime, à tort ou à raison, sous-évalué. 
2 Le dispositif narratif explique sans doute largement le succès de l'ouvrage. Une première partie sur l'improbable renversement du 20 mars (révolution? conspiration? coup d'État?) est suivie d'un « flash back » sur la période du Vol de l'Aigle ( ${ }^{\mathrm{er}}-19$ mars), puis d'une partie sur la fuite royale à Lille et à Gand, et sur le retournement de conjoncture après Waterloo. Dans chacun des quatre-vingts petits chapitres qui ponctuent l'ouvrage, l'auteur «coud» des récits individuels en une écriture polyphonique. Les bons mots abondent, telle cette célèbre réplique de Fouché : « $\mathrm{Ce}$ n'est pas moi qui trahis; [...] ce sont les événements qui à chaque instant nous trahissent » (p. 484) ou ce portrait sans concession du duc d'Orléans, aux aguets depuis l'Angleterre: "S'il ne tend pas les bras à ses séducteurs, il est disposé à se laisser violer» (p.412)... Enfin, Emmanuel de Waresquiel aime ici à télescoper passé et présent; il compare, incidemment, l'exil de 1815 à l'exode de 1940, mais suggère seulement, sans trop instrumentaliser le passé. Il récuse ainsi la comparaison, faite par certains historiens, entre la Terreur blanche de 1815 et l'épuration de 1944-1945 (p. 282).

3 L'ouvrage montre surtout l'ampleur des divisions révélées par les Cent-Jours. Les conflits symboliques, de couleurs (cocardes, drapeaux, fleurs, etc.) et de représentations du passé, ne sont pas ignorés. De même que le poids des rumeurs et des violences, dans des moments de raréfaction et de manipulation de l'information. Dans le jardin des Tuileries, le 12 mars, quelques «bonapartistes" sont achevés à coups de bâton et de parapluie, alors que monte l'angoisse d'un retour de l'« usurpateur ». Symétriquement, des volontaires royaux seront massacrés en avril 1815 par des «bleus » du Gard (à Pont-Saint-Esprit et Arpaillargues), ouvrant un nouveau cycle vindicatoire fermé par la Terreur blanche.

4 S'opposant à la légende d'un Vol de l'Aigle quasi miraculeux, l'auteur montre la résistance du Midi royaliste, le Midi des élites anciennes et nouvelles (conseils généraux et gardes nationales), mais aussi d'une fraction des classes populaires antirévolutionnaires. À cette France royaliste il oppose essentiellement la cohorte des soldats et vétérans frustrés par la première Restauration, humiliés par la résurrection de la maison militaire du roi. À la différence du 18 Brumaire, l'armée n'est pas un simple auxiliaire, elle est au cœur de la reconquête du pouvoir et des lignes de fracture des Cent-Jours. Mais les divisions sont aussi internes au royalisme, avant et après le 20 mars. Le parti de Monsieur, frère du roi, soutenu par les ducs de Berry et d'Angoulême, s'oppose avec une virulence extrême aux libéraux qui préconisent de renforcer les ouvertures prévues par la Charte de 1814 (Montesquiou, Laîné ou RoyerCollard). Blacas, le favori de Louis XVIII, est détesté de tous et finit les Cent-Jours en bouc émissaire commode.

5 Le royalisme sort-il retrempé de cet exil conflictuel ? Un romantisme du sacrifice a pu le laisser croire. Louis XVIII, podagre, a su garder de la grandeur dans ses silences. Le 19 mars (départ lacrymal du souverain hors des Tuileries) devient selon Emmanuel de Waresquiel la trame « d'une grammaire politique qu'on n'a pas assez remarquée », celle de la paix, de la liberté et de l'union, par l'évitement de la guerre civile. Les jeunes têtes brûlées de la route de Gand, les Vigny, Lamartine, Géricault croient faire l'expérience de la fidélité et de l'honneur, c'est-à-dire de la « conscience exaltée » (Vigny). Mais le désenchantement domine après Waterloo. Les "voyageurs sentimentaux»-le mot cruel est de Talleyrand, alors à Vienne - ne sauraient être dupes. Des libéralismes concurrents s'opposent, arrimés à des légitimités elles-mêmes concurrentes (celle de 
l'Acte additionnel et celle de la Charte). Le libéralisme du duc d'Orléans, déjà, pointe aussi son nez. Enfin et surtout, la deuxième restauration des Bourbons est associée à l'imaginaire de la défaite, celle de Waterloo, et de la trahison symbolique - l'abandon des trois couleurs. Si Louis XVIII a l'habileté d'exiger une entrée royale dans Paris sans la présence des alliés dans le cortège, cette collusion est dans tous les esprits. Blücher et le tsar Alexandre n'étaient pourtant guère favorables à la solution bourbonienne, à la différence de Wellington. Qu'importe, la Restauration est passée du côté des « fourgons de l'étranger ", davantage encore qu'en 1814. Une crise de la légitimité est ouverte, renforcée par la réaction royaliste de l'été et de l'automne 1815.

\section{NOTES}

1. . Emmanuel de Waresquiel, L'histoire à rebrousse-poil. Les élites, la Restauration, la Révolution, Paris, Fayard, 2005. La Revue d'histoire du XIX ${ }^{e}$ siècle a publié un compte rendu de cet ouvrage, par Jean-Claude Caron, dans son numéro 33, 2006/2, p. 169-172. 